\title{
Influências dos fatores físicos e psicológicos na sexualidade do lesado medular
}

Creuza Souza Dias*

\section{INTRODUÇÃO}

Este estudo aborda dois temas demarcados pelos padrões de "moralidade" e de "normalidade" - sexualidade e lesão medular - nos quais incidem uma carga cultural de tabus e preconceitos muito intensa.

A cultura ocidental contemporânea valoriza a aparência física, definindo as pessoas por padrões estéticos. $\mathrm{O}$ culto ao corpo belo e saudável é apregoado pela mídia. Esta é uma sociedade de consumo, onde a mercadoria é veiculada por uma propaganda embalada na beleza e na juventude. Predominando, também, a idéia de que o trabalho é que dignifica o homem.

Nossa sociedade caracteriza-se, ainda, pela desigualdade de conceituação dos papéis que homens e mulheres devem exercer. O padrão, de masculinidade é sinônimo de virilidade, de força e de dominação física. A

* Psicóloga graduada pela Faculdades Integradas da Sociedade Educacional Tuiuti. Pós-graduada Latu Sensu em Sexualidade Humana pela Faculdades Integradas da Sociedadc Educacional Tuiuti.

Recebido em 07.05.96

Aprovado em 23.05.96 
representação do papel masculino configura-se como sustentáculo da família, provedor e defensor.

Deste modo, tornar-se deficiente físico nesta sociedade é viver em permanente conflito com a incapacidade, com a dificuldade de ser aceito por si mesmo e pelos outros. O estigma da deficiência interfere em todos os aspectos da vida do portador, criando preconceitos, favorecendo a discriminação, dificultando a realização plena do ser humano.

Uma sociedade criada para os qualificados como capazes de trabalhar e produzir não se preocupa em planejar o espaço social para a circulação e o convívio com os portadores de deficiências.

Resultam deste estado de coisas preconceitos, visíveis nas ruas, na escola, no trabalho, no lazer. O deficiente, de modo geral, é visto como uma pessoa digna de piedade, incapaz de participar e de conviver. E, muitas vezes, como fruto desses preconceitos, o próprio deficiente assume a imagem preconceituosa de si mesmo. Não se percebe como um indivíduo comum, nem descobre suas próprias potencialidades, só enxergando sua deficiência.

A existência de uma visão estreita e preconceituosa pode ser encontrada mesmo nos profissionais da equipe de saúde e nos próprios pacientes. Esta postura decorre, ainda, das crenças da própria sociedade, que constrói uma sexualidade mais genitalizada e que valorize a virilidade do homem. De acordo com MURARO (1983) o corpo genitalizado do homem tem origem na idéia predominante de que seu corpo é conformado para o trabalho, para a produção, para o uso da força. A sexualidade feminina é, então, construída como complementar, é menos centrada nos órgãos genitais, é mais difusa sobre o corpo. A dominação do homem para a mulher sustenta-se por esta genitalização.

A sociedade tende a valorizar os resultados do coito e da obtenção do máximo de rendimento. A satisfação orgástica é considerada a meta a ser atingida na relação sexual, para se alcançar o máximo do prazer. Os próprios meios de comunicação, especialmente escritos e pretensamente científicos, encarregam-se de propalar esta idéia.

De modo geral, o interesse das pesquisas sobre as dificuldades que enfrentam as pessoas com deficiência física, neste caso o lesado medular, orientam seu enfoque para os aspectos neurofisiológicos. É recente, a preocupação dentro de uma perspective psicológica. Na maioria dos estudos tem-se utilizado entrevistas padronizadas e questionários, cuja validez é necessário considerar com cautela, pois trata-se de uma área do comportamento humano muito íntima e muito complexa porque envolve sentimentos, cultura, atitudes e crenças. 
Apesar de, hoje, a sociedade estar sendo mais permissiva e aberta para estas questões, continuam existindo preconceitos marginalizadores para pessoas deficientes.

Uma atenção profissional maior e o reconhecimento da sociedade de que estes indivíduos continuam muitas vezes tendo necessidades e desejos sexuais é um grande avanço. Mas, pode-se considerar apenas o começo, pois torna-se necessário encontrar novas respostas para antigas questões, até se alcançar o caminho da igualdade de oportunidades e plena integração social. (CURCOLL, 1992:13).

$\mathrm{Na}$ maior parte das vezes, as investigações sobre a sexualidade dos indivíduos portadores de lesão medular têm como enfoque somente a dimensão neurofisiológica. Embora já existam alguns estudos sobre perspectiva psicológica, ainda não se dispõem de estudos rigorosos nesta área. Talvez pela própria dificuldade por tratar-se de uma área mais afeta a tabus e preconceitos. Entretanto, sabe-se, hoje, que a compreensão dos aspectos psicológicos dos portadores de lesão medular tornam-se fundamentais, por parte dos profissionais, para auxiliar na reabilitação destes pacientes.

Em síntese, tentou-se buscar resposta à seguinte pergunta: quais os fatores físicos e psicológicos que interferem na sexualidade do homem com lesão medular completa?

E para tal tomou-se como base os indivíduos portadores de deficiência física da ADFP.

\section{DEFICIENTE E SEXUALIDADE}

\section{Deficiente}

De acordo com a Declaração dos Direitos das Pessoas Deficientes, aprovada pela Assembléia Geral da O.N.U. em 9.12.75 em seu art. $1^{\circ}$ : "O termo Pessoas deficientes, refere-se a qualquer pessoa, incapaz de assegurar por si mesma, total ou parcialmente as necessidades de uma vida individual ou normal, em decorrência de uma deficiência congênita 0,1 ou não em suas capacidades físicas ou mentais".

O termo deficiente assume um valor cultural segundo os padrões, regras e normas de cada sociedade. Além disso, a mesma deficiência pode gevar problemas diferentes conforme as circunstâncias de vida das pessoas. Segue-se que o termo deficiência é muito amplo, não existindo uma 
clara distinção entre pessoas "normais", com problemas mentais, emocionais e sociais e outras pessoas, sem estes problemas, mas portadores de uma deficiência física.

\section{Sexualidade}

Sexualidade corresponde à soma de impulso sexual, ato sexual e todos os aspectos da personalidade envolvidos na comunicação e no relacionamento interpessoal: diálogos, atividades e interesses partilhados e outras formas de expressar afeto e amor.

A sexualidade engloba atitudes e comportamentos, masculino e feminino de uma pessoa nas suas relações com o mundo. (MAIOR, 1988:16)

Entendemos a sexualidade de forma abrangente considerando sua influência sobre todos os aspectos da vida humana desde a concepção até a morte, manifestando-se em todas as fases da vida (infância, adolescência, fase adulta, terceira idade) sem distinção de raça, cor, sexo, deficiências, etc.; considerando a genitalidade como uma de suas formas de expressão, porém não a única.

\section{Sexualidade e deficiência}

Falar de "sexualidade" ou de "deficiência" suscita muitas controvérsias, face aos preconceitos, falta de informações e tabus que envolvem este assunto.

Quando se fala em sexualidade, deve-se entendê-la como um conjunto de comportamentos que englobam, não apenas o ato sexual em si, mas também, interesses, atividades e formas de expressar afeto, carinho de dar e de receber amor e que proporcionam prazer ao indivíduo.

\section{Lesão Medular}

Por lesão medular entendemos um acometimento grave e trágico na vida de uma pessoa. Freqüentemente, causa a perda permanente da sensibilidade e/ou motricidade abaixo do nível medular acometido, deixando o indivíduo tetraplégico ou paraplégico. 
As conseqüências da lesão medular são irreversíveis e permanentes e consistem em paralisia das extremidades, alterações da sensibilidade, falta de controle sobre as esfíncteres, tanto vesical como retal, transtornos no Sistema Nervoso Autônomo e alterações nos diferentes componentes da sexualidade e fertilidade.

Depois de uma lesão da medula espinhal, se podem produzir uma série de síndromes neurológicas, com seqüelas que atinge o campo da sexualidade.

Freqüentemente, essa lesão causa a perda permanente da sensibilidade e/ou motricidade abaixo do nível medular acometido, levando o indivíduo à tetraplegia ou paraplegia, além de causar significativas alterações viscerais, sexuais, tróficas e outras.

De modo geral, o comprometimento da integridade funcional da medula espinhal acarreta transtornos deficitários, tais como: da motricidade, dos aspectos tróficos dos tecidos, dos reflexões, da função sexual e outros.

Embora o paciente portador de lesão medular apresente alterações na função sexual, persiste a sua sexualidade já que esta é inerente ao ser humano e está influenciada por fatores genéticos, psicológicos e culturais. A função sexual é parte integrante dessa sexualidade e pode ser definida como um complexo mecanismo neuro-psico-endócrino-vascular.

Entende-se por paraplegia, causada por lesão medular traumática, um quadro de déficit motor e sensitivo com alterações importantes de funções como circulação, bexiga, intestinos, controle térmico e atividade sexual, com paralisia total dos membros inferiores.

Para fins deste estudo, nossa abordagem limita-se às alterações sexuais no homem portador de paraplegia por etiologia traumática.

\section{Paraplegia e as dimensões da sexualidade}

A sexualidade constitui uma das dimensões do indivíduo; não se refere apenas a seu potencial para reagir a estímulos eróticos. E ela própria é multidimensional: comportando as dimensões físico-biológica, psicológica e sócio-cultural.

\section{Dimensão Físico-Biológica}

Dizem CURCOLL e VIDAL que das múltiplas menos-valia que Pode sofrer o homem, a lesão ou enfermidade da medula é uma das calami- 
dades mais devastadoras na vida humana. A lesão medular, de acordo tom estes autores, "consiste na interrupção das vias nervosas, de ,forma parcial ou completa, secundária a uma enfermidade, por traumatismo ou de origem congênita, que afeta a medula espinhal ao longo de seu espaço, pela coluna vertebral”. (CURCOLL e VIDAL, 1992:25)

Paraplegia causada por lesão medular entende-se como um quadro de déficit motor e sensitivo tom alterações importantes de funções como circulação, bexicga, intestinos, controle térmico e atividade sexual, com paralisia total dos membros inferiores.

As alterações da função sexual no homem portador de lesão medular, envolvem a ereção, a ejaculação, o orgasmo e a fertilidade.

\section{Dimensão psicológica}

É fundamental a compreensão da pessoa humana como um ser total que, por alguma circunstância tornou-se paraplégica. NEDER (1961) sublinha que não se pode atribuir uma estrutura de personalidade específica para os paraplégicos.

Eles diferem entre si, diferem dos indivíduos que não são portadores de deficiência física e como estes, apresentam personalidade própria, pessoal e individual.

NEDER avaliando 66 (sessenta e seis) casos de paraplégicos em processo de reabilitação explica que têm papel importante na sexualidade destas pessoas as experiências de vida anteriores à instalação da paraplegia e as adquiridas no meio familiar. (NEDER, 1961:45)

Sobre a sexualidade, é necessário considerar também as experiências de vida anteriores à instalação da paraplegia, em especial, as adquiridas no meio familiar. Enfatiza-se o peso da sociedade face a valores preconceituosos sobre o homem impotente que passa a ser objeto de depreciação, parceiro inaceitável para a mulher, incapaz de ser pai e inadequado como homem em todo o sentido da palavra. (NEDER, 1961:45)

Há de se destacar que a compreensão das reações dos indivíduos paraplégicos envolvem atividades psíquicas conscientes e inconscientes e condições de sua auto-imagem e esquema corporal, uma vez que o paraplégico deverá integrar uma nova imagem corporal a reformular seu auto-conceito. 
MAIOR (1988) referindo-se aos problemas psicológicos do paraplégico, no qual se refere à sexualidade, destaca três áreas relacionadas: imagem corporal, auto-estímulo e identidade sexual.

\section{A imagem corporal}

Imagem corporal é entendida como a percepção que se tem do próprio corpo e a crença de como este corpo é percebido pelos outros.

A imagem do corpo é muito fortemente socializada e culturalizada, pois seus modelos variam segundo o sistema interpretativo dos grupos humanos.

As imagens que o indivíduo constrói sobre si mesmo são várias.

Ao lado da imagem do corpo existem as imagens social, sexual, intelectual e outras possíveis. Cada situação que a pessoa enfrenta, vem à tona uma destas imagens, que inconscientemente é adequada às circunstâncias do momento.

Assim, as imagens negativas geralmente são agrupadas, resultando que uma pessoa com uma imagem fraca sobre si própria em relação ao seu corpo, mostra a tendência de unir a esta imagem, uma imagem fraca em relação à sua vida social, sexual, familiar, cultural. (MAIOR, 1988:41)

\section{A identidade sexual}

O estereótipo de masculinidade assenta-se na idéia de força, agressão e dominação física e ereção. Disto decorre a necessidade de o paraplégico ser orientado na busca de sua identidade sexual, por ser a maneira de cada um expressar-se como homem. (MAIOR, 1988:25)

Os pontos básicos para o reequilíbrio da personalidade são: elaborar a nova imagem corporal, recuperar a auto-estima e buscar sua identidade sexual. Então, surge "a confiança para reassumir um papel sexual e social positivo". (MAIOR, 1988:25)

MONEY e TUCKE observam a necessidade de diferenciar identidade sexual e papel sexual. Assim, identidade sexual é o seu senso de si mesmo como homem ou como mulher. O papel sexual inclui tudo o que se pensa e se sente, o que se diz e se faz, que indique a si e aos outros que se é homem ou mulher. Como afirmam estas autoras: "A identidade sexual e papel sexual não são duas coisas distintas, são aspectos diferentes da mesma coisa, assim como os proverbiais dois lados da mesma 
moeda. A sua identidade sexual é experiência interna do seu papel sexual; o seu papel sexual é a expressão da sua identidade sexual. $O$ termo 'identidade papel sexual' enfatiza esta unidade". (MONEY e TUCKE, 1981:12)

Considerando ainda que, como o estereótipo de masculinidade está impregnado por idéias de força, agressão e dominação física, os portadores de paraplegia necessitam ser orientados na busca de sua identidade sexual, que é a maneira de cada um expressar-se como homem em nosso universo sócio-cultural. (SALIMENE, 1992:42)

\section{Auto-estima}

A auto-estima está associada à avaliação da imagem corporal que o deficiente físico faz de si próprio. Entendida, aqui como a confiança e a satisfação que o próprio corpo transmite ao indivíduo. MAIOR afirma que: "afetada a auto-estima estará também distorcida a percepção de adequação à vida, dando espaço a sentimento de inferioridade e abandono". (MAIOR, 1988:25)

As pessoas que convergem a auto-estima para a capacidade física têm mais dificuldade de se reajustar após a instalação da lesão. MAIOR declara que há uma relutância pela maioria dos deficientes em abandonar a imacgem corporal anterior. Este fato foi observado por RYIAN (1961) em estudo sobre os sonhos dos paraplégicos, constatando que, em seus sonhos, eles não se vêem deficientes. (MAIOR, 1988:25)

O paraplégico precisa construir uma nova imagem, inclusive a partir das reações dos outros ao "novo" corpo. Essa reestruturação passa também pelo conhecimento de suas limitações e pela incorporação que passo cadeiras de rodas, muletas, coletores de urina - numa nova convivência com o próprio corpo.

\section{Dimensão sócio-cultural}

A dimensão psicossocial da sexualidade inclui fatores psicológicos - emoções, pensamentos e personalidade - combinados a elementos sociais, o modo como as pessoas interagem.

MURARO fala que o sexo encontra-se na conjunção de dois eixos da vida humana: o individual e o coletivo. É no sexo que se localiza o elemento mais importante da nossa interioridade, é onde interagem libido, 
pulsões, desejos, funções, prazeres e desprazeres. MURARO considera, ainda, que no sexo está também o elemento substancial da "economia política da vida". Isto é a regulação das populações tom todos os efeitos globais de reprodução e controle nas sociedades ocidentais modernas. (MURARO, 1983:21)

O modelo caracteristicamente masculino da sociedade brasileira é de dominação, gerando o fenômeno do machismo. Assim, o paraplégico, a despeito de passar a portar uma deficiência física, continua convivendo no interior do próprio modelo sócio-cultural que o produziu, e agora o exclui. Nesse processo de exclusão, também sua sexualidade é negada pela sociedade.

O homem que agora é portador de deficiência e que exercia antes um papel dominante no plano social e cultural, no que se refere ao desempenho de sua sexualidade, se vê agora atingido. Com a aquisição da limitação física - e, por decorrência, com o aparecimento de barreiras que frente a ele se instalaram no plano de sua vivência social - este papel dominante poderá ser desestabilizado, trazendo-lhe conflitos, frustrações, e a imposta condição de marginalidade, incapaz.

Com toda essa cobrança social e pessoal será extremamente difícil reabilitar o paraplégico para uma nova forma de ser, se perceber e agir como homens nesta sociedade. E como diz SALIMENE, "que esses indivíduos sejam orientados e estimulados a desenvolver a sua sexualidade de forma gratificante, por onde passarão também as suas possibilidades de estabelecer relações de afeto e de convívio interpessoal". (SALIMENE, 1992:59)

\section{MATERIAL E MÉTODOS}

A coleta de dados foi realizada por meio de entrevista dirigida com questões semi-estruturadas para se conhecer a qualidade do relacionamento sexual antes e após a lesão, e assim perceber as mudanças ocorridas.

As entrevistas foram efetuadas, no período de um mês, na sede da Associação dos Deficientes Físicos do Paraná, em horário regular em que os associados compareciam (segundas, quartas e sextas, das 14:00 às 17:00 horas).

Procedeu-se a um teste piloto tom a ficha de entrevista realizada com 5 (cinco) pessoas do mesmo grupo, para se verificar se todas as questões estavam claras e saber quais as questões que precisavam ser 
cuidadosamente controladas para se evitar antagonismo ou constrangimento dos entrevistados. Buscou-se, também, verificar se existiam questões que não provocassem a informação que se pretendia obter.

As informações obtidas na entrevista foram registradas nos formulários individuais no momento da coleta dos dados.

Foram entrevistados, ao todo, 50 (cinqüenta) indivíduos do sexo masculino.

O tratamento dos dados tiveram como base as seguintes categorias de análise: imagem corporal, auto-estima e identidade masculina.

\section{Resultados Obtidos}

Em relação à faixa etária predominou a faixa entre 31 e 40 anos (40\%) seguindo-se de 21 a $30(28 \%)$ e de 41 a 50 (28\%), com apenas $4 \%$ na faixa entre 15 a 20 anos.

O estado civil, antes do acidente, é representado por $70 \%$ solteiros e $26 \%$ casados, e apenas $4 \%$ separados. Após o acidente, foi mínima a diferença, pois 5 (cinco) dos solteiros, casaram-se, entretanto o número de casados permaneceu porque houve 5 (cinco) separações.

Em relação ao grau de instrução predominou o 29 grau completo (44\%), seguindo-se o 19 grau incompleto (22\%) e o superior (20\%), não se registrando nenhum analfabeto.

Ao se analisar as conseqüências do acidente constatou-se que o relacionamento com a parceira, antes do acidente para a maioria era bom ou ótimo (78\%). Após o acidente, mais da metade da população relacionada teve sérias alterações ou rompeu-se.

Em relação ao trabalho, quase metade do grupo mudou de função e para $20 \%$ não houve alteração. É significativo o número dos que se retiraram do trabalho, através de pedido ou aposentadoria (30\%). A incidência mais alta dos que se demitiram ou se aposentaram verificou-se para os que estão entre 30 e 50 anos, em plena idade de produtividade.

Apesar de, para mais da metade da população estudada, ter havido readaptação ao trabalho, ainda restou mais ou menos $40 \%$ de pessoas que parecem ainda necessitar de uma política de adaptação ou reencaminhamento profissional.

No entanto, em relação às atividades sociais, verificou-se que a metade dos entrevistados abandonaram todas as atividades sociais. 
Porém quando esta mesma questão se fez por tipos ou atividades sociais a resposta cai para $24 \%$ especificando-se posteriormente o que foi deixado para traz.

Os indivíduos na faixa de 15 a 20 anos foram os mais atingidos em relação à prática das atividades sociais.

Estes dados indicam a carência de um trabalho social mais intenso com o objetivo de reintegrar os lesados medulares no convívio da sociedade.

Ao se analisar a manifestação da sexualidade verificaram-se os tópicos seguintes:

\section{Vida Sexual}

Em relação ao desejo sexual, constatou-se que era "freqüente" e "muito freqüente" em 92\% dos entrevistados e após o acidente este percentual cai para 16\%; enquanto que "pouco freqüente" e "raro" passou a incidir $72 \%$.

A ereção sofreu significativas mudanças para este grupo de lesados medular, verificando-se $88 \%$ com "frequiência" e "muita freqüência" antes do acidente, e $16 \%$, após o acidente. Em referência à ejaculação constatou-se que após o acidente $52 \%$ não têm mais ejaculação, enquanto antes do acidente este percentual era zero. Observou-se que a fase do orgasmo foi a mais prejudicada, correspondendo a $2 \%$ às respostas para os itens "raramente" e "nunca atinge" para antes do acidente, a 72\% para estes mesmos itens após o acidente.

Para mais da metade dos entrevistados, as atividades sexuais reiniciaram após um ano de ocorrência da lesão e para $12 \%$ não houve reinício.

\section{Vida Sexual}

Em relação ao desejo sexual, constatou-se que era "freqüente" "muito frequiente" em $92 \%$ dos entrevistados e após o acidente este percentual cai para 16\%; enquanto que "pouco freqüente" e "raro" passou a incidir $72 \%$.

A ereção sofreu significativas mudanças para este grupo de lesados medular. verificando-se $88 \%$ com "freqüência" e "muita freqüência" antes do acidente e $16 \%$ após o acidente. Em referência à ejaculação constatou-se que após o acidente $52 \%$ não têm mais ejaculação, enquanto antes 
do acidente este percentual era zero. Observou-se que a fase do orgasmo foi a mais prejudicada, correspondendo a $2 \%$ às respostas para os itens "raramente" e "nunca atinge para antes do acidente e $72 \%$ para estes mesmos itens após o acidente.

Para mais da metade dos entrevistados as atividades sexuais reiniciaram após um ano de ocorrência da lesão e para $12 \%$ não houve reinício.

Verificou-se que a maior parte das pessoas entrevistadas mudou de posição para fazer sexo. Em referência ao tipo de relação sexual, em torno da metade prefere o sexo vaginal e $32 \%$ aos jogos preliminares. Não ocorreu nenhum registro sobre preferência de sexo oral ou anal.

$\mathrm{Na}$ vida atual do grupo analisado, as alternativas de gratificação sexual entre o casal que têm preponderância são abraços e beijos (80\%). Quase a totalidade raramente se masturba.

com relação à atitude do entrevistado, em referência à sua deficiência, verificou-se que $90 \%$ ao tomar consciência do fato foi tomado por um sentimento de "revolta/raiva" e na situação presente $56 \%$ passou a mantee "uma boa convivência".

Podem-se resumir os resultados da análise nor seguintes itens:

1. como consequiência do acidente, o relacionamento com a companheira sofreu sérias alterações;

2. os indivíduos atingidos pela lesão medular sofreram também com as alterações em relação ao trabalho e às atividades sociais;

3. em relação à manifestação da sexualidade constatou-se que todas as fases do ato sexual foram prejudicadas, mas a mais atingida foi o orgasmo;

4. o tratamento de reabilitação mostrou-se efetivo para mais da metade da população pesquisada;

5. a meiosis dos pesquisados busca alternativas de gratificação sexual.

\section{DISCUSSÃO}

Confirmou-se nests investigação a afirmação de que se confirma nesta investigação a afirmação de que a função sexual do lesado medular é mais prejudicada na seguinte ordem: orgasmo, ejaculação e ereção. 
Segundo LIANZA (1985), a ereção está diretamente relacionada ao nível da lesão. A ejaculação, por ser um mecanismo reflexo mais complicado é mais vulnerável que a ereção. Esta função é rara nos pacientes com lesão completa. O orgasmo pode ser sentido tanto por portadores de lesão completa tipo N.M.I., como por alguns com lesão completa.

O significado do sexo mantêm-se inalterado para a maioria dos indivíduos, contudo a disfunção sexual é um dos principais problemas da lesão raduimedular.

O deficiente enfrenta um período de transição até encontrar novos rumos para sua reidentificação sexual, mas com orientação correta e par ticipação de sua parceira pode, muitas vezes, ter uma vida sexual ativa. Excluído pela sociedade graças aos padrões a aos preconceitos estabelecidos. pela cultura do belo, da aparência física, da valorização do saudável e do perfeito, do estereótipo de masculinidade impregnado pela idéia de força e de dominação física.

A violência urbana não só o produz, como também o agride limitando suas possibilidade como ser integral.

Ser portador de deficiência nesta sociedade é viver em permanente conflito com a aceitação por si mesmo e pelo outro. Deste modo, quando um indivíduo sofre uma lesão medular, e se vê repentinamente limitado em alguma de suas funções, tem a percepção que daquele momento em diante, as suas perspectivas de futuro foram truncadas.

São inúmeras as dificuldades que ele passa para enfrentar, desde adapter-se ao novo estado físico, à imagem corporal, até a aprender a conviver com todos estes problemas.

Pelos dados coletados e analisados, observou-se que, no plano afetivo para este universo, a sexualidade se manifesta e é vivenciada como a realização de uma necessidade básica. Ela acontece apesar dos limites, dos traumas, das dificuldades, ao toque, às carícias, aos gestos. O sexo é visto como algo bom, positivo; para alguns, a única coisa que lhes restou, mesmo aos bocados.

Pode-se concluir que a reconstrução da identidade masculina do homem com lesão medular passa pela via de reconstrução de sue sexualidade. Quando percebida e vivenciada sob uma perspectiva mais ampla de sua vida cotidiana, parece ser vivida com mais êxito. Deste modo, a retomada dos papéis sociais e familiares estão intimamente ligados também à manifestação da sexualidade. 


\section{REFERÊNCIAS BIBLIOGRÁFICAS}

1. CURCOLL, M. L. \& VIDAL, J. Sexualidad y lesion medular. Barcelona-Espanha: Fundació Institut Guttmann.

2. LIANZA, S. "A lesão de medula”. In: LIANZA, S. et all. Medicina de reabilitação. Rio de Janeiro: Guanabara Koogan, 1985.

3. MAIOR, Izabel Maria Maderia de Loureiro. Reabilitação sexual do Paraplégico e tetraplégico. Rio de Janeiro: Revinter, 1988.

4. MONEY, John e TUCKE, Patrícia. Os papéis sexuais. São Paulo: Brasiliense, 1981.

5. MURARO. Sexualidade da mulher brasileira. Corpo e classe social no Brasil. 3. cd. Petrópolis: Vozes, 1983.

6. SALIMENE, Arlete Camargo de Melo. Paraplegia por lesão medular traumática em homens e sexualidade. São Paulo: PUC, 1992. Dissertação Mestrado (mimeogr.). 